\title{
Holstein cow vocalization behavior during oestrus periods
}

\begin{abstract}
In this study, it is aimed to investigate the estrus behavior characteristics of cows by observing them comparatively and to reveal especially the sound related features in detail. For this purpose cows were observing during the oestrus time for their vocalization behavior. Oestrus affected by many hormones secreted by the animal during oestrus periods. There are several estrus detection methods, but efficiency differs depending on many factors. Efficient oestrus detection effect reproductive performance, while providing a significant increase in productivity in herd management and eliminating factors that inhibit reproductive performance.
\end{abstract}

This research was investigated between February -May 2017 at Private dairy Farm which is located Mediterranean region of Turkey. At the beginning experiment, cows were selected depending on their characteristics as an example at the beginning of the experiment in order to minimize the experimental error and avoid the effects caused by the differences between the groups. Holstein milking cows which selected similar lactation number $(3,1 \pm 0,84)$, body weight $(664,69 \pm 7,45)$ and milk yield $(25,96 \pm 0,49)$ were used. 150 head cows were synchronized with their estrus using the ovsych protocol and 10 cows were taken observation pen. The barn where the experiment is conducted is a free-stall barn and there are also walking areas for animals. Oestrus behavior of the cows was recorded by the researchers using directly observation methods. During oestrus period vocalizations behavior increased from $12,67 \pm 2,11$ to $61,46 \pm 12,18$ calls. During post oestrus period vocalization of cows decreased to $24,00 \pm 2,01$. There are big variations between the cow vocalization. But cow calling; a statistically significant difference was found between the number of repetitions of sound; repetition was significantly longer in heat cows $(p<0.01)$. Results suggest that more studies are required to draw strong conclusions regarding detailed information about oestrus situation of cow.

Keywords: dairy cow, vocalizations, oestrus detection, behavior
Volume 4 Issue 6 - 2019

\author{
Serap Göncü,' Sibel Bozkurt² \\ 'Professor, Department of Animal Science, Çukurova University, \\ Turkey \\ 2MSc Student, Department of Animal Science, Çukurova \\ University, Turkey
}

\begin{abstract}
Correspondence: Serap Göncü, Professor, Department of Animal Science, Çukurova University,Adana, Turkey, Tel 905333606282, Email serapgoncu6@gmail.com
\end{abstract}

Received: November 19, 2019 | Published: December 05, 2019

\section{Introduction}

Accurate oestrus detection is the most important issue for profitable dairy cattle farm management. Nowadays, there are many methods used in oestrus detection. To determine successful estrus in dairy cattle, the behavioral characteristics of the estrus female must be known in a timely and accurate manner. A cow standing to be mounted is the most known accurate sign of estrus. An estrous cow usually stands to be mounted 20 to 55 times during estrous period. Each mount lasts three to seven seconds. But most mounting occurs in early morning or during the later evening hours. The heat cows exhibit mounting activity when they are not distracted by farm activities such as feeding, milking, and barn cleaning. The data may further indicate that cattle prefer to mount during the cooler times of the day. Secondary signs are also used for oestrus detection which is vary in duration and intensity. Another sign of oestrus is to bellowing of cow during estrus. Understanding animal voice characteristics could provide an efficient management tool to dairy farm reproduction management. The most attractive point of acoustic monitoring is that determination occurs without physical contact. Early detection of heat is a very important issue in the herd management of cows. ${ }^{1,2}$ Oestrus affected by hormones secreted by the animal at certain interval. There are several methods of estrus detection, but when detected in a timely manner, reproductive performance in livestock increases, while providing a significant increase in productivity in herd management and eliminating factors that inhibit reproductive performance. ${ }^{3}$ Another sign of oestrus is to bellowing behavior of the cows. Recently many studies focused on cattle vocalization to asses oestrus time to more convenient way. Vocalization can be sign of pain, oestrus, separation from her calf, and hunger or thirst, but also about the animal's individuality. Xin et al. ${ }^{4}$ and Riede et al. ${ }^{5}$ reported that different sounds produced in cattle during hunger and thirst and some disorder. Cattle may bellow more frequently during estrus. Although these are not definitive signs of heat, cows exhibiting such behavior should be watched closely for standing behavior. Ikeda and Ishii. ${ }^{6}$ suggested that the vocalization of a cow contains much information about the animal's extraordinary situations. Although the small number of animals in the herd provides convenience, it is very difficult to do this only with observation in a professional enterprise. Nowadays, there is predominantly observation-related heat detection, but when the herd increases, it becomes difficult to observe the heat and also leads to loss of labor and time. ${ }^{7}$ Meen et al. ${ }^{8}$ Showed that there was a statistical difference between behaviors and voices by determining the maximum frequency of each call in Hertz $(\mathrm{Hz})$ of bovine behaviors and voices. Bradbury and Vehrencamp ${ }^{9}$ assume that sound frequencies can provide information about the physical state as well as their mental state in communicating with other environmental factors in animals. Watts and Stookey ${ }^{10}$ stated that voice behavior is a useful tool to study the physical and psychological state of an animal. They also found that the sounds that animals make among themselves 
are perceived as meaningful sounds for each other and play an important role in their interaction with their environment. It is also suspected that the vocalizations of cattle contain information about age, sex, dominance status, and stage in the estrous cycle. ${ }^{11}$ Increased vocalizations have also been observed in cows transitioned from tie stalls to free stalls ${ }^{12}$ and in calves during social play, ${ }^{13}$ suggesting that a vocal response is not specific to negative events. Moreover, vocal responses are highly variable among individuals even in response to clearly negative events. Latest studies focused on cow vocalization for signal for the detection of these conditions by recent technologic applications. Jahns ${ }^{14}$ classified the cow's specific calls into seven emotional states. Consequently, vocalization can be used as a signal for the detection of these conditions by objective, non-contact, and remote sensing techniques. ${ }^{6}$ Generally high frequency calls relate to negative affect and low-frequency calls relate to more positive effect but some studies have reported no difference in the maximum frequency of vocalizations produced during social interaction, sexual behavior, and behaviors such as fleeing. ${ }^{8}$

Considering that the technology that dominates in every field will develop more in the following years, it cannot be considered that animal husbandry is independent of this field. In this study, it is aimed to investigate the estrus behavior characteristics of cows by observing them comparatively and to reveal especially the sound related features in detail. For this purpose cows were observing during the oestrus time for their bellowing activity detection.

\section{Material and methods}

Research was investigated between February and May 2017 at Private dairy Farm which is located Mediterranean region of Turkey. At the beginning experiment, cows were selected depending on their characteristics as an example at the beginning of the experiment in order to minimize the experimental error and avoid the effects caused by the differences between the groups. Holstein milking cows which selected similar lactation number $(3,1 \pm 0,84)$, body weight $(664,69 \pm 7,45)$ and milk yield $(25,96 \pm 0,49)$ were used. 150 head cows were synchronized with their estrus using the ovsych protocol and 10 cows were taken observation pen. The barn where the experiment is conducted is a free-stall barn and there are also walking areas for animals. Oestrus behavior of the cows was recorded by the researchers using directly observation methods. All cows carried plastic identification collars and had been temporary number paint, making accurate cow identification possible from a distance of up to 10 meters. During the experiment, selected animals were observed for signs of oestrus during the experiment. Student who was specially trained for this study, and who had no other tasks at the farms during the experiment, observed the cows, working in 12 hour shifts. For vocalization records, cows stayed in her normal surroundings within view and vocal contact of other cows. Visual observation of estrus signs was carried out daily from 07:00 and 19:00h

In the experiments, total mixture ration (TMR) feeding system was applied and mixed feed ratio in TMR composition: 60: 40. TMR material composition used in the experiment (air dry) and calculated nutrient content were given Table 1 . The total mixture was composed of corn silage (50\%), alfalfa hay (25\%) and wheat straw (25\%). Total mixture rations were prepared daily, were given to the animals as two meals in the morning 07.00 and at 16.00 in the afternoon. The feeds were given in the concrete feeders $(28 \mathrm{~m}$ per group, $0.70 \mathrm{~m}$ feeder per cows), except the third experimental group animals carried out in the individual trial unit. The cows in all experimental groups were provided with free access to fresh water continuously.

Table I TMR material composition used in the experiment (air dry) and calculated nutrient content

\begin{tabular}{|c|c|}
\hline Feeds & $\%$ \\
\hline Corn silage & 25,00 \\
\hline Clover straw & 8,00 \\
\hline Wheat straw & 12,00 \\
\hline Wheat Fracture & 6,00 \\
\hline Full-fat soy & 9,00 \\
\hline Sunflower meal & 11,30 \\
\hline Wheat bran & 20,10 \\
\hline Molasses & $\mathrm{I}, 50$ \\
\hline Condensed molasses & 3,00 \\
\hline Salt & 0,70 \\
\hline DCP & $\mathrm{I}, 20$ \\
\hline Limestone & 2,10 \\
\hline Vitamin-mineral mixture & 0,10 \\
\hline \multicolumn{2}{|l|}{ Nutrient composition (\%) } \\
\hline Dry matter & 62,9 \\
\hline Crude protein & 15,8 \\
\hline Crude oil & 5,5 \\
\hline ADF (Acid Detergent Fiber) & 22,4 \\
\hline NDF (Neutral Detergent fiber) & 17,9 \\
\hline Starch & 15,2 \\
\hline Sugar & 8,7 \\
\hline Ash & 10,8 \\
\hline
\end{tabular}

Vitamin-mineral mix: Vitamin A I5.000 $000 \mathrm{IU}$, Vitamin D3 3.000.000 IU, Vitamin E $30.000 \mathrm{mg}$, Manganese $50000 \mathrm{mg}$, Iron $50000 \mathrm{mg}$, Zinc $50.000 \mathrm{mg}$, Organiç chelated zinc $25.000 \mathrm{mg}$, Copper $10.000 \mathrm{mg}$, Cobalt $130 \mathrm{mg}$, lodine $800 \mathrm{mg}$, Selenium 130mg

The data obtained by observing the heat-synchronized cows were recorded daily. Also oestrus determined by visual observations such as mucous vaginal discharge, restlessness, sniffing of the vagina of other cow, resting with chin on other cow and standing behavior were recorded. The bellowing behavior characteristics of the cows in the oestrus period and the cows in the trial were monitored during this period and features such as continuous bellowing period and time interval were determined. SPSS 24.0 Statistical Software was used for statistical analysis. Descriptive statistical methods (mean, standard deviation, median, frequency, ratio). The chi-square tests were used for the comparison of qualitative data. The results were evaluated at $95 \%$ confidence interval and $\mathrm{p}<0.05$ significance level. 


\section{Results and discussion}

Good reproduction management is a key factor for successful dairy farming. Traditionally, oestrus detection is performed by visual observation of the dairy herd but this procedure particularly difficult on large dairy farms. Oestrus detection has many difficulties because of many reasons. Oestrus detection generally depends on behavioral changes of cows such as standing, mounting, walking, restlessness, chin pressing. ${ }^{15}$ The aim of the present study was to determine mounting activity, mucous vaginal discharge, restlessness, sniffing of the vagina of other cow, resting with chin on other sign of oestrus period. The results of the mounting activity, mucous vaginal discharge, restlessness, sniffing of the vagina of other cow, resting with chin on other cow are given in Table 2.

Table 2 The results of the mounting activity, mucous vaginal discharge, restlessness, sniffing of the vagina of other cow, vocalization

\begin{tabular}{|c|c|c|c|c|}
\hline & Prooestrus & Oestrus & Postoestrus & \multirow{3}{*}{ Significancy } \\
\hline & $\overline{\mathbf{x}} \mathbf{\pm} \mathbf{S x}$ & $\overline{\mathbf{x}} \pm \mathbf{S} \bar{x}$ & $\bar{x} \pm \mathbf{S} \bar{x}$ & \\
\hline & (Min. - Max.) & (Min. - Max.) & (Min. -Max.) & \\
\hline Mounting activity & $7 / 15$ & $3 / 15$ & 0 & 0 \\
\hline Mucous Vaginal Discharge & 0 & $8 / 15$ & 0 & 0 \\
\hline Restlessnes & $7 / 15$ & $12 / 15$ & 0 & 0 \\
\hline Sniffing of the vagina of other cow & $9 / 15$ & $7 / 15$ & $2 / 15$ & 0 \\
\hline \multirow{2}{*}{ Vocalizations number } & $|2,67 \pm 2| \mid$, & $61,46 \pm 12,18$ & $24,00 \pm 2,01$ & \multirow[t]{2}{*}{0} \\
\hline & $(8,|2| 7,2 \mid)^{b}$ & $(35,32-87,60)^{a}$ & $(\mid 9,68-28,31)^{b}$ & \\
\hline Vocalization duration (second) & $3,60 \pm 0,40(2-7)^{\mathrm{b}}$ & $25,40 \pm 3,26(12-55)^{a}$ & $3,46 \pm 0,44(1-6)^{b}$ & 0 \\
\hline Vocalize cow & $5 / 15$ & $9 / 15$ & $2 / 15$ & 0 \\
\hline
\end{tabular}

Mounting activity mainly determined at prooestrus time which can be accepted sign of approaching heat. Mounting activity performed much less in oestrus time. A cow standing to be mounted is the most known accurate sign of estrus. An estrous cow usually stands to be mounted 20 to 55 times during estrous period. Each mount lasts three to seven seconds. But most mounting occurs in early morning or during the later evening hours. All cows vocalized during the observation period. The number of vocalizations differed considerably between cows and ranged between 8 and 87 vocalizations per cows during the observation time. There is a strong increase in vocalization in -oestrus period. During oestrus vocalizations increased from $12,67 \pm 2,11$ to $61,46 \pm 12,18$ calls. During post oestrus period vocalization of cows decreased to $24,00 \pm 2,01$. There are big standard errors between the cow vocalization numbers. But cow calling; a statistically significant difference was found between the number of repetitions of sound; repetition was significantly longer in heat cows $(p<0.01)$. The presence of vaginal discharge showed big variation between animals. This vaginal discharge is produced in the cervix and accumulates with other fluids in the vagina before, during, and shortly after estrus. This discharge looks like long viscous, clear elastic strands which generally can be detected hang from the vulva. Mucus also can be detected on the tail, thighs, flanks, or perineal region as shiny path. Heat cows generally are more restless and alert to their surroundings. When interact with other heat cows, try to mount other cows. Research shows heat cows spend less time resting than other cows. They generally remain standing and alert while others are resting. Sniffing the genitalia and licking the vulva of other cows occur much more frequently with cows in proestrus and estrus. The studies on the sound of cattle have recently been intensified and the variable sound and vocal characteristics of cattle have been studied with different methods. Our results showed that the during the oestrus period cows calling levels increase. Our results showed similar trend with other research results. ${ }^{12,13}$ Cows in oestrus display the many behaviors more intensively: restlessness, mounting, allowing mounting without standing, sniffing the vulva of another cow, resting the chin on the back of another cow, licking, rubbing, and aggressiveness. Many technologic aids try to use Oestrus detection generally depends on behavioral changes of cows such as standing, mounting, walking, restlessness, chin pressing to detect oestrus. Results of oestrus detection varied depending on the many factor such as threshold value, cow number, barn style, and the statistical method for data analysis. The detection error rates between 17 and 55\% and indicate a large number of false warnings. Still technologic aids have some limiting factor, and sector still search another accurate and economic solution to solve this problem. ${ }^{16}$

\section{Conclusion}

In the period of oestrus, the addressing behavior offers significant advantages especially for automation systems and therefore, it attracts great attention. However, the change in the vocal behavior according to the oestrus period has not been examined clearly yet. Vocalization differences determination can be a solution to help heat detection problem. Our results showed that the during the oestrus period cows vocalization increase. But vocalization number of each cows showed large individual variability between animals. More complex analysis can be an alternate solution for the detection of this phenomenon.

\section{Acknowledgments}

None.

\section{Funding}

None. 


\section{Conflicts of interest}

The authors declare that they have no conflict of interest.

\section{References}

1. Firk R, Stamer E, Junge W, et al. Automation of oestrus detection in dairy cows: a review. Livest Prod Sci. 2002;75:219-232.

2. Saint-Dizier M, Chastant-Maillard S. Towards an automated detection of oestrus in dairy cattle. Reprod Domest Anim. 2012;47(6):1056-1061.

3. Lehrer AR, Lewia GS, Aizinbud E. Oestrus detection in cattle: recent developments. Anim Reprod Sci. 1992;28:355-362.

4. Xin H, De Shazer JA, Leger DW. Pig vocalizations under selected husbandry practices. ASAE. 1989;32(6):2181-2184.

5. Riede T, Tembrock G, Herzl H, et al. Vocalization as indicator for disorders in mammals. The Journal of the Acoustical Society of America. 1997;102(5).

6. Ikeda Y, Ishii Y. Recognition of two psychological conditions of a single cow by her voice. Comput Electron Agric. 2008;62(1):67-72.

7. Jiménez A, Bautista F, Galina CS, et al. Behavioral characteristics of Bos indicus cattle after a superovulatory treatment compared to cows synchronized for estrus. Asian-Aust J Anim Sci. 2011;24(10):1365-1371.

8. Meen GH, Schellekens MA, Slegers MHM, et al. Sound analysis in dairy cattle vocalizations as a potential welfare monitor. Computers and Electronics in Agriculture. 2015;118:111-115.
9. Bradbury JW, Vehrencamp SL. Principle of animal communication. Sinauer Associates, USA: Massachusetts; 1998.

10. Watts JM, Stookey JM. Vocal behaviour in cattle:the animal's commentary on its biological processes and welfare. Applied Animal Behaviour Science. 2000;67(1-2):15-33.

11. Schön PC, Hämel K, Puppe B, et al. Altered vocalization rate during the estrous cycle in dairy cattle. J Dairy Sci. 2007;90(1):202-206.

12. Pavlenko A, Lidfors L, Arney DR, et al. Behavior and performance of dairy cows after transfer from tied to cubicle housing. J Appl Anim Welf Sci. 2018;21(1):82-92.

13. Wagner K, Barth K, Hillmann E, et al. Mother rearing of dairy calves: Reactions to isolation and to confrontation with an unfamiliar conspecific in a new environment. Appl Anim Behav Sci. 2013;147(1-2):43-54.

14. Jahns G. Call recognition to identify cow conditions-a call-recogniser translating calls to text. Comput Electron Agric. 2008;62(1):54-58.

15. Eradus WJ, Rossing PH, Hogewerf E, et al. Signal processing of activity data for oestrus detection in dairy cattle. In: Ipema, Lippus, Metz, Rossing, editors. Proceedings of the International symposium on prospects for automatic milking. EAAP Publication No. 65, The Netherlands: Pudoc Scientific, Wageningen; 1992:360-369.

16. Göncü S, Koluman N. The sensor technologies for more efficient cow reproduction systems. MOJ Ecology \& Environmental Sciences. 2019;4(3):128-131. 